\title{
Cholesterol reduction from milk using $\beta$-cyclodextrin immobilized on glass
}

\author{
Muhammad Nazir Tahir, ${ }^{*}$ Chanho Kwon, ${ }^{*}$ Daham Jeong, ${ }^{*}$ Eunae Cho, ${ }^{*}$ Seung R. Paik, $†$ and Seunho Jung* \\ *Department of Bioscience and Biotechnology \& Center for Biotechnology Research in UBITA, Konkuk University, Seoul 143-701, \\ Republic of Korea \\ †Department of Chemical \& Biological Engineering, Seoul National University, Seoul 151-742, Republic of Korea
}

\section{ABSTRACT}

$\beta$-Cyclodextrin $(\beta-\mathrm{CD})$ was converted into $\beta$-CDundecenyl ether by chemical modification and subsequently covalently attached to a glass surface. The functionalized glass surface was characterized by static water contact angle and x-ray photoelectron spectroscopy. Both techniques confirmed that an excellent monolayer of $\beta-C D$ was formed on the glass surface. The $\beta$-CD solid surface was used to reduce cholesterol levels in milk. In $4 \mathrm{~h}, 73.6 \%$ of the cholesterol was extracted at $25^{\circ} \mathrm{C}$ with shaking at $170 \mathrm{rpm}$. This is the highest value ever reported for milk using $\beta$-CD immobilized on a solid surface. The same surface was repeatedly used for 10 cycles and maintained its efficiency with $72 \pm 2 \%$ cholesterol reduction observed in all the cycles. X-ray photoelectron spectroscopy analysis completed after 5 and 10 cycles of cholesterol reduction showed that the $\beta$-CD on the glass surface was not degraded. The high efficiency and long-term stability of the functional monolayer was attributed to the specific structure of $\beta-C D$, which is composed of a relatively low number of functional groups and long spacer chain lengths that provide great flexibility.

Key words: cholesterol reduction, $\beta$-cyclodextrin, glass immobilization, repeated use

\section{INTRODUCTION}

A strong statistical relationship exists between high serum cholesterol levels and cardiovascular diseases (Gurr, 1992; Kim et al., 2004). Therefore, food companies have conducted many studies to reduce cholesterol levels by using physical, chemical, and biological methods (Kwak et al., 2004; Hansel et al., 2007; Dias et al., 2010). The methods included blending vegetable oils, adsorption with saponin and digitonin to form cholesterol complexes (Micich, 1990), degradation of cholesterol by cholesterol oxidizers, removal by supercritical fluid extraction (Arul et al., 1988), and extraction with

Received November 7, 2012.

Accepted March 12, 2013.

${ }^{1}$ Corresponding author: shjung@konkuk.ac.kr high-methoxyl pectins (Garcia Rojas et al., 2007) and organic solvents (Larsen and Froning, 1981). In previous years, many studies have indicated that $\beta$-cyclodextrin $(\boldsymbol{\beta}-\mathbf{C D})$ can be used to reduce cholesterol levels in dairy products (Shim et al., 2003; Kim et al., 2005; Lee et al., 2007). In most of these studies (Schwartz et al., 1967; Lee et al., 1999; Kim et al., 2005), $\beta$-CD powder was used. In other studies, cholesterol reduction from dairy products involved the use of $\beta$-CD cross-linked with epichlorohydrin (Kim et al., 2004) or with adipic acid (Han et al., 2007; Han et al., 2008) and on glass beads (Kwak et al., 2004).

Modified solid surfaces such as glass have numerous applications in many areas of science and technology (Wang et al., 2005). However, the application of $\beta$-CD covalently attached to a glass surface for cholesterol reduction from dairy products is not common. $\beta$-Cyclodextrin immobilized surfaces have many advantages over free $\beta$-CD used in traditional methods, including simple recovery after the extraction of cholesterol, repeated use, and the possibility for continuous large-scale processes.

Naturally abundant glass, which is mainly composed of $\mathrm{SiO}_{2}$, has been investigated as an efficient immobilization support (Taylor et al., 2005) because it is affordable and recyclable. Indeed, a previous study has shown that it was used as an immobilization support for cholesterol removal from milk (Kwak et al., 2004). However, that study found that only 37 to $41 \%$ of the cholesterol could be removed from milk by using $\beta-C D$ immobilized on glass beads (Kwak et al., 2004). Here, we report an effective method for the covalent immobilization of $\beta-\mathrm{CD}$ on a glass-slide surface for cholesterol removal from milk. The present glass-slide support with $\beta$-CD is relatively cheap and a more highly characterized material for food industrial applications. In addition, the cholesterol removal efficiency $(73.6 \%)$ for milk obtained in this study, using modified surfaces, is the highest reported to our knowledge. Furthermore, we believe that the alkene-based monolayers reported in this work, which have relatively long carbon chains and minimal functional groups to avoid any unnecessary inter- or intra-molecular interactions, are stable, can be repeatedly used for several cycles without effi- 
ciency loss, and can be stored for a long period without degradation.

\section{MATERIALS AND METHODS}

\section{Materials}

Standard milk was purchased from a local retail store. $\beta$-Cyclodextrin ( $\geq 97 \%)$, ammonium chloride, 1-( $p$-toluenesulfonyl)-imidazole, and tetrahydrofuran were purchased from Sigma-Aldrich (Seoul, Korea). $N, N$-dimethyl formamide (DMF) was from Fluka (Kyunggi-do, Korea), 10-undecen-1-ol and sodium hydride were from Tokyo Chemical Industry Co. Ltd. (Tokyo, Japan), sodium hydroxide was from Duksan Pure Chemical Co. (Ansan, Korea), and deuterated dimethyl sulfoxide (DMSO- $\boldsymbol{d}_{\boldsymbol{6}}$ ) was from Cambridge Isotope Laboratories Inc. (Andover, MA). The glass microscope slides $(76 \times 26 \times 1 \mathrm{~mm})$ were purchased from Paul Marienfeld GmbH \& Co. KG (Lauda-Königshofen, Germany).

\section{Experimental Method}

Water was purified using the Direct-Q Millipore water purification system from Sam Woo S\&T Co. Ltd. (Seoul, Korea). The $\beta$-CD was dried under vacuum until a constant weight was observed, whereas the other chemicals were used without further purification. The NMR spectra were recorded on a Bruker AMX spectrometer (Bruker Corp., Billerica, MA) at $500 \mathrm{MHz}$. Thin-layer chromatography (TLC) was performed on Merck Kieselgel 60 F254 plates (Merck KGaA, Darmstadt, Germany). The TLC spots were visualized by exposure to $5 \%$ sulfuric acid-ethanol and $140^{\circ} \mathrm{C}$. X-ray photoelectron spectroscopy (XPS) spectra were recorded using a Sigma Probe photoelectron spectrometer (Thermo VG Scientific, West Sussex, UK). Highresolution spectra were obtained using monochromatic $\mathrm{Al}-\mathrm{K} \alpha \mathrm{X}$-ray radiation at $15 \mathrm{kV}$ and $100 \mathrm{~W}$ and an analyzer pass energy of $50 \mathrm{eV}(1.0-\mathrm{eV}$ step size) for wide scans and $20 \mathrm{eV}$ (0.1-eV step size) for narrow scans. All high-resolution spectra were corrected with a linear background before fitting. The wettability of the modified surfaces was determined by automated static water contact angle measurements using a Krüss DSA $10 \mathrm{Mk} 2$ contact angle measuring instrument (Krüss GmbH, Hamburg, Germany). The volume of the drop of demineralized water was $3 \mu \mathrm{L}$.

\section{Synthesis of $\beta$-Cyclodextrin-Undecenyl Ether}

Mono-6-( $p$-toluenesulfonyl)-6-deoxy-cyclodextrin ( $\beta$-CD-OTs) was synthesized from $\beta-\mathrm{CD}$ as previously described (Wang et al., 2011) and was then converted into $\beta$-CD-undecenyl ether. For this purpose, NaH (100 $\mathrm{mg}$ of $60 \%$ dispersion in mineral oil, $2.50 \mathrm{mmol}$ ) was cleaned several times with pentane and then dry DMF $(4 \mathrm{~mL})$ was added to the dry round bottom flask under $\mathrm{N}_{2}$ atmosphere. Next, 10-undecen-1-ol (0.34 g, $2 \mathrm{mmol}$ ) in dry tetrahydrofuran $(4 \mathrm{~mL})$ was added dropwise while keeping the flask at $0^{\circ} \mathrm{C}$. After $5 \mathrm{~h}, \mathrm{H}_{2}$ evolution was finished and the $\beta$-CD-OTs ( $1 \mathrm{~g}, 0.77 \mathrm{mmol})$ dissolved in dry DMF $(4 \mathrm{~mL})$ was slowly added. The reaction was left stirring overnight under $\mathrm{N}_{2}$. Subsequently, the reaction was quenched with water $(10 \mathrm{~mL})$. Unreacted 10-undecen-1-ol was separated by extracting the mixture with diethyl ether $(3 \times 10 \mathrm{~mL})$. The aqueous phase containing the product was dried under vacuum, and the product was purified by flash column chromatography (i-Pr-OH: $\left.\mathrm{H}_{2} \mathrm{O}: \mathrm{EtOAc:} \mathrm{NH}_{4} \mathrm{OH} / 5: 5: 1: 1\right), 823.84 \mathrm{mg}$, $0.64 \mathrm{mmol}, 82 \%$ (where i-Pr-OH $=$ isopropyl alcohol and EtOAc = ethyl acetate). Thin-layer chromatography $\mathrm{R}_{\mathrm{f}}$ : 0.63 (i-Pr-OH: $\mathrm{H}_{2} \mathrm{O}: \mathrm{EtOAc:} \mathrm{NH}_{4} \mathrm{OH} / 5: 5: 1: 1$ ), $1-\mathrm{H}$ NMR $\left(500 \mathrm{MHz}, \mathrm{DMSO}-d_{6}\right) \delta=1.29(\mathrm{~s}, 10 \mathrm{H}), 1.43$ $(\mathrm{m}, 2 \mathrm{H}), 1.51(\mathrm{~m}, 2 \mathrm{H}), 2.18(\mathrm{~m}, 2 \mathrm{H}), 3.31-3.61(\mathrm{~m}$, $40 \mathrm{H}), 3.37(\mathrm{~m}, 2 \mathrm{H}), 4.13(\mathrm{~m}, 1 \mathrm{H}), 4.27-4.29(\mathrm{~m}, 1 \mathrm{H})$, $4.33(\mathrm{t}, 1 \mathrm{H}), 4.41(\mathrm{~m}, 2 \mathrm{H}), 4.48(\mathrm{t}, 3 \mathrm{H}), 4.72(\mathrm{~d}, 2 \mathrm{H})$, $4.80(\mathrm{~m}, 5 \mathrm{H}), 5.02(\mathrm{~m}, 2 \mathrm{H}), 5.64-5.73(\mathrm{~m}, 14 \mathrm{H}), 5.82$ $(\mathrm{m}, 1 \mathrm{H})$, where $\mathrm{R}_{\mathrm{f}}=$ retention factor, $\mathrm{NMR}=$ nuclear magnetic resonance, $\delta=$ chemical shifts in NMR values, $\mathrm{s}=$ singlet, $\mathrm{m}=$ multiplet, $\mathrm{t}=$ triplet, and $\mathrm{d}=$ doublet.

\section{Modification of a Borosilicate Microscope Glass Slide}

A borosilicate glass microscope slide was cleaned with acetone, $n$-hexane, methanol, and ethanol (3 times per solvent) and then sonicated for 5 min per solvent. All the solvents were HPLC grade. The glass slide was etched for $30 \mathrm{~min}$ in a freshly prepared solution of $\mathrm{HCl}$ $(37 \%)$ and ethanol (1:1, vol/vol). After etching, the samples were rinsed and sonicated with deionized water and ethanol for 5 min per solvent and dried under a nitrogen stream. Immediately after cleaning, the glass slide was transferred into a glass reaction cell. The glass slide was coated with $\beta$-CD-undecenyl ether dissolved in DMSO $(30 \mathrm{mg} / \mathrm{mL})$ using a micropipette while under nitrogen atmosphere before being tightly sealed. The reaction cell was dipped into liquid $\mathrm{N}_{2}$ to freeze the coated $\beta$-CD-undecenyl ether and allowed to liquefy again at room temperature under vacuum. This freezethaw cycle was repeated 3 times to remove the trace amounts of oxygen and moisture that could enter the reaction cell during sample coating. Finally, the reaction cell was backfilled with nitrogen, dipped into a silicon oil bath, and heated at $110^{\circ} \mathrm{C}$ for $24 \mathrm{~h}$ while the nitrogen pressure was maintained. The modified glass slide was removed from the reaction cell and thoroughly washed with deionized water, $n$-hexane, and acetone, and then 
sonicated for $5 \mathrm{~min}$ per solvent. The modified glass slide was then dried under a nitrogen stream and characterized by static water contact angle and XPS. The reproducibility of the process was confirmed by recording the XPS spectra of 3 independently prepared glass surfaces.

\section{Cholesterol Extraction From Milk and Analysis by HPLC}

The glass surface modified with $\beta-C D$ was placed in a glass cell. A milk volume of equal weight to the glass slide was added to the cell, which was then tightly closed and placed in a shaker at $25^{\circ} \mathrm{C}$ and $170 \mathrm{rpm}$. The same treatment was performed using an unmodified glass slide of the same type as a control. Samples were withdrawn after $2,4,6$, and $8 \mathrm{~h}$. For cholesterol determination, the $\beta$-CD-treated milk $(1 \mathrm{~mL})$ was transferred into a test tube and combined with $10 \% \mathrm{KOH}$ (ethanolic; $1 \mathrm{~mL}$ ). The test tube was tightly closed and heated at $70^{\circ} \mathrm{C}$ for $30 \mathrm{~min}$ to complete saponification. After cooling back to room temperature, $3 \mathrm{~mL}$ of water was added, and the unsaponified fraction was extracted with $n$-hexane $(3 \times 5 \mathrm{~mL})$. The organic layers were collected and evaporated under vacuum. The residue was redissolved in methanol $(1 \mathrm{~mL})$ and analyzed by HPLC. As a control, $1 \mathrm{~mL}$ of untreated milk was used, and the same process was performed in parallel.

A Jupiter C18 HPLC column $(5 \mu M, 250 \times 4.60 \mathrm{~mm}$; Shimadzu Corp., Kyoto, Japan) was used for quantitative analysis of cholesterol by the method developed by
Oh et al. (2001). The analysis was performed at $30^{\circ} \mathrm{C}$ with a flow rate of $1.5 \mathrm{~mL} / \mathrm{min}$ and a mobile phase of acetonitrile:isopropanol (89:11, vol/vol). Elution was monitored at $205 \mathrm{~nm}$. For quantitative analysis, cholesterol solutions of different concentrations were run in the HPLC under the same conditions, and a straight line was drawn between the concentration and peak area $\left(\mathrm{R}^{2}=0.99\right)$. Cholesterol reduction from HPLC data was calculated as follows:

Cholesterol reduction $(\%)=100-\left(\frac{\text { cholesterol in } \beta \text {-CD-treated milk }}{\text { cholesterol in untreated milk }} \times 100\right)$.

\section{RESULTS AND DISCUSSION}

\section{Immobilization of $\beta-C D$ on the Glass Surface}

Modified $\beta$-CD ( $\beta$-CD-undecenyl ether) was covalently attached to a glass surface by the thermal method (Figure 1). The modified surface was characterized by static water contact angle and XPS. The static water contact angle of etched glass is very low $\left(<15^{\circ}\right)$ due to its extremely hydrophilic surface (Nguyen et al., 2011). After attachment of the $\beta-\mathrm{CD}$ monolayer to the surface, its hydrophilicity decreased, and the water contact angle increased from $<15^{\circ}$ to $54 \pm 2^{\circ}$, thereby indicating the successful formation of a $\beta-\mathrm{CD}$ monolayer.

The XPS wide-scan spectrum (Figure 2a) revealed an increase in $\mathrm{C}(0.00$ to $36.87 \%)$ and decrease in $\mathrm{O}(67.24$ to $37.70 \%)$ and $\mathrm{Si}(32.76$ to $25.44 \%$ ) content on the

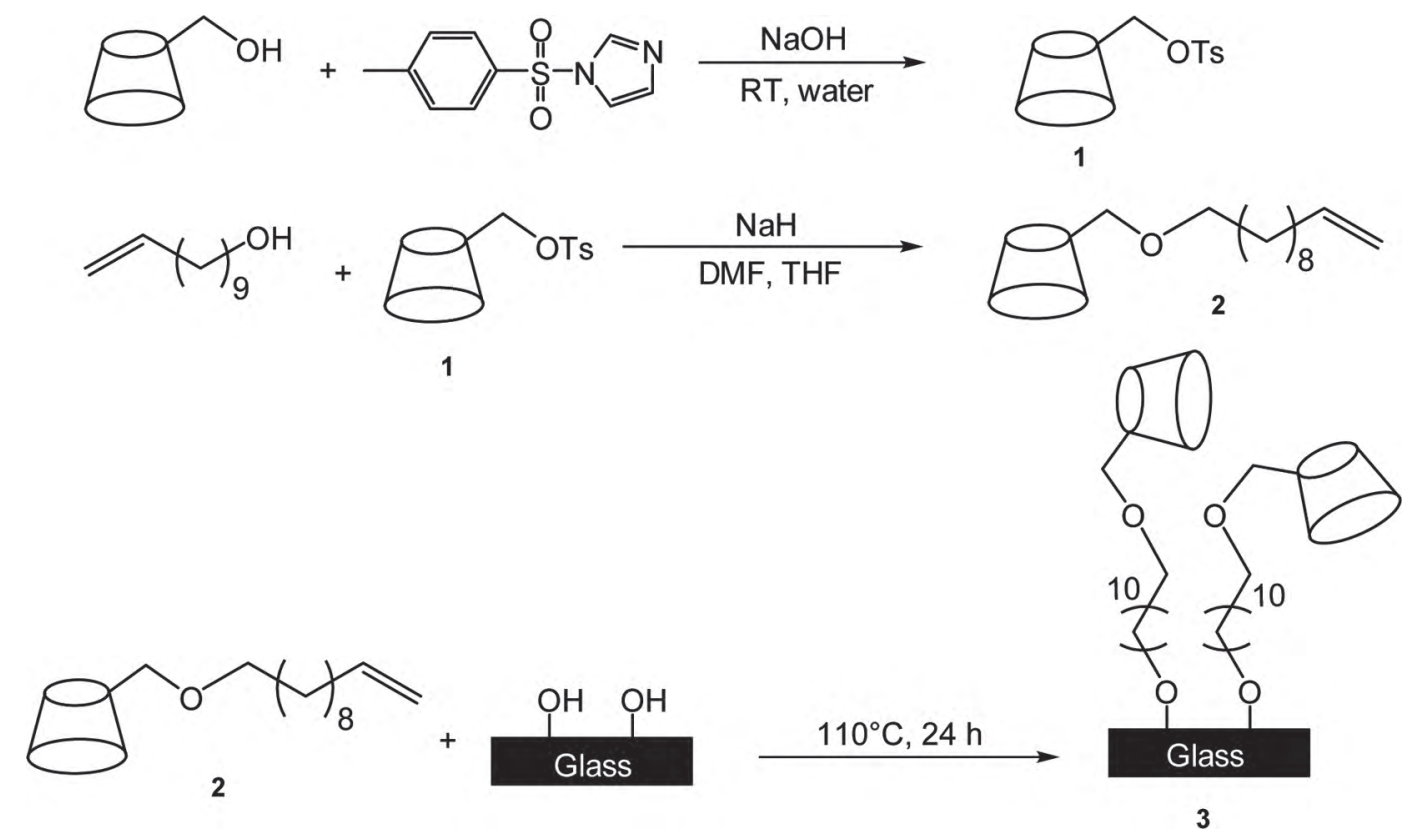

Figure 1. Modification of a glass slide with altered $\beta$-cyclodextrin ( $\beta$-CD). 1 = mono-6-(p-toluenesulfonyl)-6-deoxy-cyclodextrin ( $\beta$-CDOTs); $2=\beta$-CD-undecenyl ether; $3=$ modified glass slide; $\mathrm{RT}=$ room temperature; $\mathrm{DMF}=N, N$-dimethyl formamide; THF $=$ tetrahydrofuran. 
experimental glass slide compared with the blank glass (see Table 1). This result also indicated the successful attachment of $\beta$-CD-undecenyl ether to the glass surface. In the XPS $\mathrm{C}_{1 \mathrm{~s}}$ narrow-scan spectrum (Figure $2 \mathrm{~b}$ ), signals corresponding to $\mathrm{C}-\mathrm{C}(285 \mathrm{eV})$ and C-O (286.45 $\mathrm{eV}$ ) appeared in the experimental sample. Agreement between the $\mathrm{C}-\mathrm{O}: \mathrm{C}-\mathrm{C}$ ratio (theoretical 4.88, experimental 4.31) also confirmed that an excellent $\beta-\mathrm{CD}$ monolayer was formed on the glass surface.

\section{Cholesterol Extraction from Milk}

We focused mainly on the covalent immobilization of $\beta-C D$ on the glass surface, detailed characterization of the modified surface, changes occurring on the modified surface during its use in cholesterol reduction, and the stability of the $\beta$-CD monolayer on the glass surface during repeated use. All cholesterol extraction experiments were conducted in a glass cell at $25^{\circ} \mathrm{C}$ that was shaken at $170 \mathrm{rpm}$. Previous studies have reported the optimization of conditions such as mixing duration, effect of tube size, and mixing temperature (Kwak et al., 2004).

The cholesterol-extraction experiments using $\beta$-CD immobilized on the glass surface were performed as described in the experimental section. The samples removed after 2, 4, 6, and $8 \mathrm{~h}$ (Table 2) showed almost no change in the cholesterol content after $4 \mathrm{~h}$ of incubation with $\beta-C D$ immobilized on the glass surface. As a control, an unmodified glass slide was also used in parallel under the same conditions; however, no reduction in cholesterol was observed. Therefore, all samples were incubated with the $\beta$-CD modified surface for $4 \mathrm{~h}$.

\section{Repeated Use of the Modified Glass Surface}

Cross-linked $\beta$-CD can be efficiently used for several cycles (Kim et al., 2004; Kwak et al., 2004; Han et al., 2005); however, its collection from milk after cholesterol extraction is a laborious and time-consuming process. Therefore, the procedure can be simplified by the use of $\beta-C D$ covalently attached to a solid support such as glass. Moreover, such a process can be used to immobilize $\beta-\mathrm{CD}$ onto a spiral column/tube or on a microreactor surface that can be used in a continuous process at the industrial scale. Repeated use of such surfaces can make the process simple and economical. Importantly, recovery of the modified surface should be as simple as possible.

We have developed a method using $\beta$-CD covalently attached to a glass surface, which can be easily removed from milk after the cholesterol extraction process and can be repeatedly used after soaking in an acetic acid and butanol mixture, as previously described (Han et

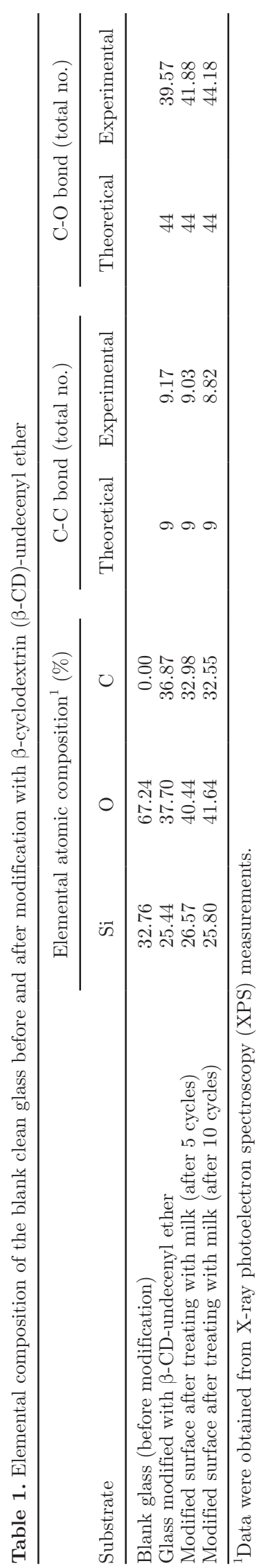


Table 2. Effect of incubation time on cholesterol reduction using $\beta$-cyclodextrin ( $\beta$-CD) immobilized on a glass surface

\begin{tabular}{lc}
\hline $\begin{array}{l}\text { Incubation } \\
\text { time }(\mathrm{h})\end{array}$ & $\begin{array}{c}\text { Cholesterol } \\
\text { reduction }(\%)\end{array}$ \\
\hline 2 & 71.4 \\
4 & 73.6 \\
6 & 73.1 \\
8 & 73.5 \\
\hline
\end{tabular}

al., 2007). We used our modified glass surface 10 times for cholesterol extraction from milk and the HPLC results (Figure 3) showed almost no change in the cholesterol reduction over time. In the 10 cycles, $72 \pm 2 \%$ cholesterol was extracted from the milk using the same glass surface functionalized with $\beta$-CD. During repeated

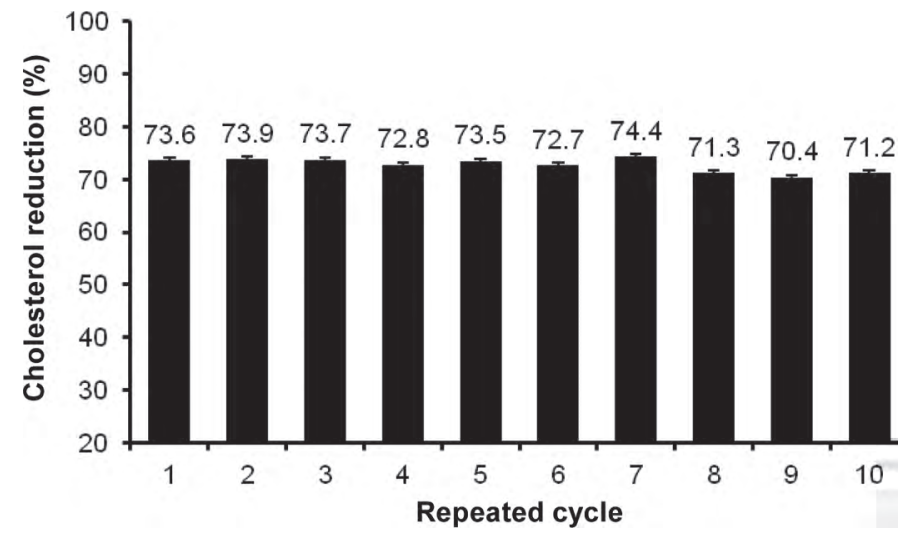

Figure 3. Cholesterol reduction from milk by repeated use of $\beta$-cyclodextrin ( $\beta$-CD) immobilized on glass.
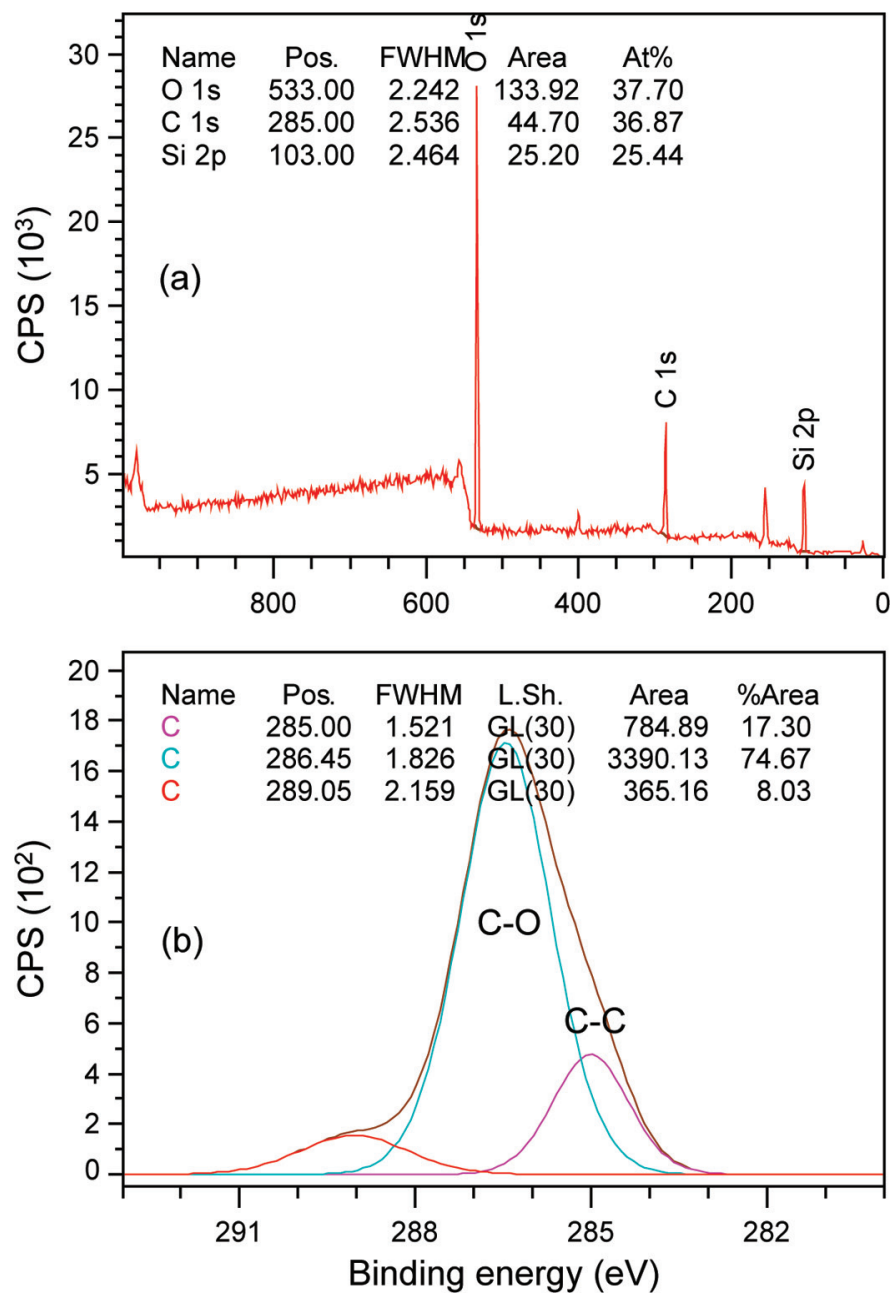

Figure 2. X-ray photoelectron spectroscopy (XPS) spectra of a glass surface modified with $\beta$-cyclodextrin $(\beta-C D)$ : (a) wide scan; (b) $\mathrm{C}_{1 \mathrm{~s}}$ region narrow scan. $\mathrm{CPS}=$ counts per second; Pos. $=$ position; FWHM = full width at half maximum; At $\%=$ atomic percentage L.Sh. = Lorentzian shape; GL = Gaussian Lorentzian. Color version in the online PDF.
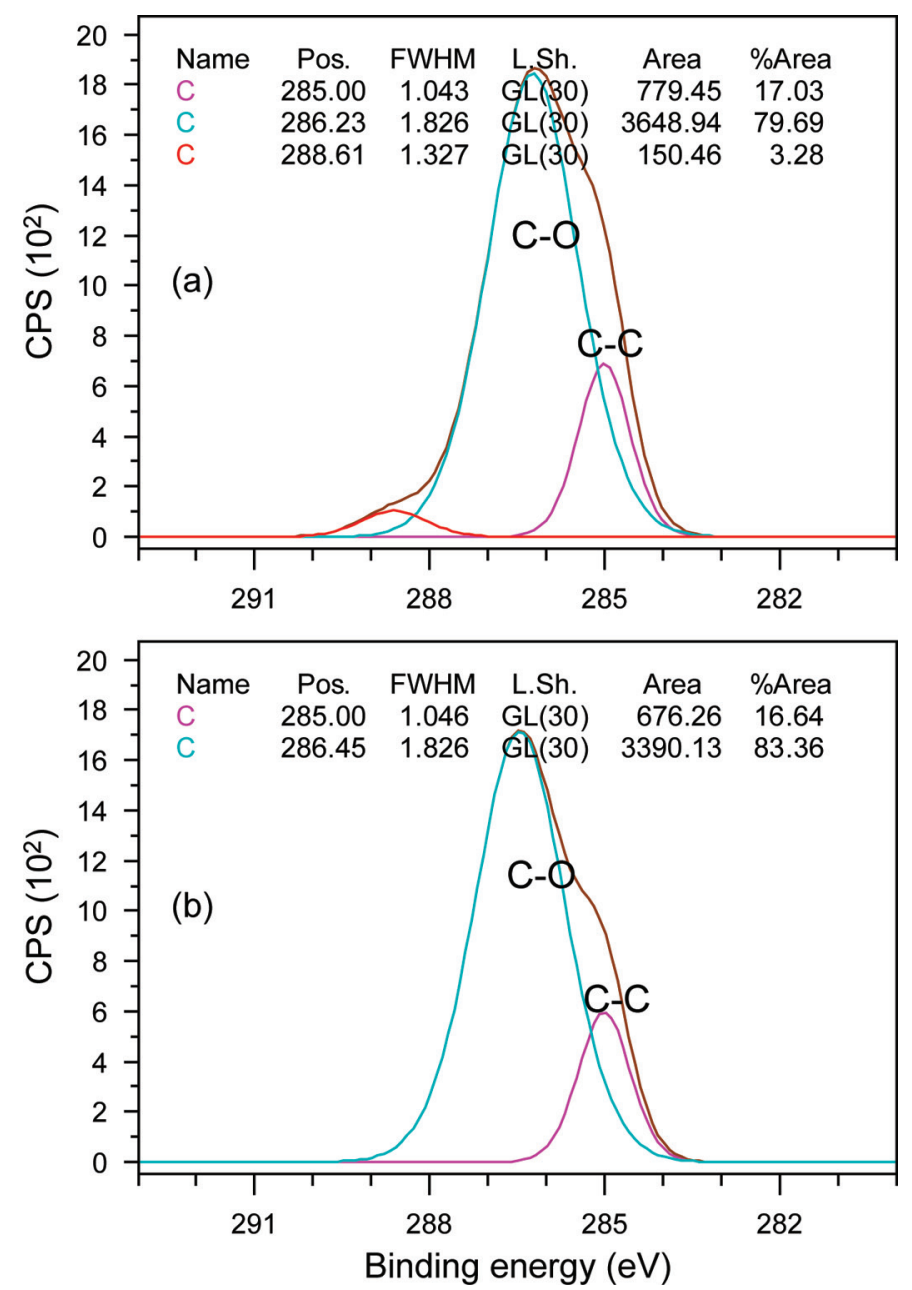

Figure 4. X-ray photoelectron spectroscopy (XPS) $\mathrm{C}_{1 \mathrm{~s}}$ narrowscan spectra of glass surface modified with $\beta$-cyclodextrin $(\beta-C D)$ after 5 (a) and 10 (b) cycles of cholesterol reduction from milk. CPS $=$ counts per second; Pos. $=$ position; $\mathrm{FWHM}=$ full width at half maximum; L.Sh. = Lorentzian shape; GL = Gaussian Lorentzian. Color version in the online PDF 
use, the incubation time was $4 \mathrm{~h}$ because no change in cholesterol reduction was observed after $4 \mathrm{~h}$ during the preliminary experiments (Table 2). The glass surface after modification with $\beta$-CD was characterized with static water contact angle and XPS (Figure 2). The XPS spectra (Figure 4a) of the same surface recorded after 5 and 10 cycles of repeated use showed almost no change in elemental composition or relative number of specific bond linkages. A slight increase in $\mathrm{Si}$ and $\mathrm{O}$ and a minor decrease in $\mathrm{C}$ content were observed (Table 1) and, therefore, the surface can be considered stable under the conditions used in this study.

Interestingly, the experimental value of different bond linkages on the freshly modified surface slightly deviated from the theoretical value (Table 1). This deviation decreased after 5 cycles and was almost in agreement with the theoretical values after 10 cycles. The reason for the variation was the presence of an unwanted signal in the narrow-scan $\mathrm{C}_{1 \mathrm{~s}}$ spectrum of the freshly modified surface at $289.05 \mathrm{eV}$ (Figure 2b). We were not able to explain this unexpected signal and, therefore, we assumed that it was probably due to a side product attached to the glass surface. The intensity of this signal decreased from 8.03 to $3.28 \%$ after 5 cycles and totally disappeared after 10 cycles. The XPS spectra recorded after 10 cycles not only confirmed the removal of the side product, but also indicated the stability of the monolayer on the glass surface during repeated use. Thus, long alkyl chains and the absence of unnecessary functional groups in our monolayer (Figure 1) were the main reasons for this method's excellent efficiency, long-term stability, and durability.

\section{CONCLUSIONS}

$\beta$-Cyclodextrin immobilized on a glass surface can be used as a solid support for cholesterol reduction from milk. Characterization of the modified glass surface by XPS and static water contact confirmed the successful modification of the glass surface. The observed reduction in cholesterol $(72 \pm 2 \%)$ investigated in this study is the highest value ever reported in the literature using immobilized $\beta$-CD. Moreover, this method allows easy separation, repeated use, long-term stability, and the possibility of applying such modified surfaces in continuous processes at the industrial scale.

\section{ACKNOWLEDGMENTS}

Financial support for this research work was provided by Konkuk University (Seoul, Korea) in 2012.

\section{REFERENCES}

Arul, J., A. Boudreau, J. Makhlouf, R. Tardif, and B. Grenier. 1988. Distribution of cholesterol in milk fat fractions. J. Dairy Res. $55: 361-371$.
Dias, H. M. A. M., F. Berbicz, F. Pedrochi, M. L. Baesso, and G. Matioli. 2010. Butter cholesterol removal using different complexation methods with beta-cyclodextrin, and the contribution of photoacoustic spectroscopy to the evaluation of the complex. Food Res. Int. 43:1104-1110.

Garcia Rojas, E. E., J. S. dos Reis Coimbra, L. A. Minim, and J. F. Freitas. 2007. Cholesterol removal in liquid egg yolk using high methoxyl pectins. Carbohydr. Polym. 69:72-78.

Gurr, M. I. 1992. Dietary lipids and coronary heart disease: Old evidence, new perspective. Prog. Lipid Res. 31:195-243.

Han, E.-M. S.-H. Kim, J. Ahn, and H.-S. Kwak. 2005. Cholesterol removal from homogenized milk with crosslinked $\beta$-cyclodextrin by adipic acid. Asian-australas. J. Anim. Sci. 18:1794-1799.

Han, E.-M., S.-H. Kim, J. Ahn, and H.-S. Kwak. 2007. Optimizing cholesterol removal from cream using $\beta$-cyclodextrin cross-linked with adipic acid. Int. J. Dairy Technol. 60:31-36.

Han, E. M., S. H. Kim, J. Ahn, and H. S. Kwak. 2008. Comparison of cholesterol-reduced cream cheese manufactured using crosslinked $\beta$-cyclodextrin to regular cream cheese. Asian-australas. J. Anim. Sci. 21:131-137.

Hansel, B., C. Nicolle, F. Lalanne, F. Tondu, T. Lassel, Y. Donazzolo, J. Ferrières, M. Krempf, J.-L. Schlienger, B. Verges, M. J. Chapman, and E. Bruckert. 2007. Effect of low-fat, fermented milk enriched with plant sterols on serum lipid profile and oxidative stress in moderate hypercholesterolemia. Am. J. Clin. Nutr. 86:790-796.

Kim, S. H., J. Ahn, and H. S. Kwak. 2004. Crosslinking of $\beta$-cyclodextrin on cholesterol removal from milk. Arch. Pharm. Res. 27:1183-1187.

Kim, S.-H., E.-M. Han, J. Ahn, and H.-S. Kwak. 2005. Effect of crosslinked $\beta$-cyclodextrin on quality of cholesterol-reduced cream cheese. Asian-australas. J. Anim. Sci. 18:584-589.

Kwak, H. S., S. H. Kim, J. H. Kim, H. J. Choi, and J. Kang. 2004. Immobilized $\beta$-cyclodextrin as a simple and recyclable method for cholesterol removal in milk. Arch. Pharm. Res. 27:873-877.

Larsen, J. E., and G. W. Froning. 1981. Extraction and processing of various components from egg yolk. Poult. Sci. 60:160-167.

Lee, D. K., J. Ahn, and H. S. Kwak. 1999. Cholesterol removal from homogenized milk with $\beta$-cyclodextrin. J. Dairy Sci. 82:23272330

Lee, S.-J., J.-H. Hwang, S. Lee, J. Ahn, and H.-S. Kwak. 2007. Property changes and cholesterol-lowering effects in evening primrose oil-enriched and cholesterol-reduced yogurt. Int. J. Dairy Technol. 60:22-30.

Micich, T. J. 1990. Behavior of polymer-supported digitonin with cholesterol in the absence and presence of butter oil. J. Agric. Food Chem. 38:1839-1843.

Nguyen, A. T., J. Baggerman, J. M. J. Paulusse, C. J. M. van Rijn, and H. Zuilhof. 2011. Stable protein-repellent zwitterionic polymer brushes grafted from silicon nitride. Langmuir 27:2587-2594.

Oh, H. I., T. S. Shin, and E. J. Chang. 2001. Determination of cholesterol in milk and dairy products by high-performance liquid chromatography. Asian-australas. J. Anim. Sci. 14:1465-1469.

Schwartz, D. P., C. R. Brewington, and L. H. Burgwald. 1967. Rapid quantitative procedure for removing cholesterol from butter fat. J. Lipid Res. 8:54-55.

Shim, S. Y., J. Ahn, and H. S. Kwak. 2003. Functional properties of cholesterol-removed whipping cream treated by $\beta$-cyclodextrin. J. Dairy Sci. 86:2767-2772.

Taylor, R. H., S. M. Fournier, B. L. Simons, H. Kaplan, and M. A. Hefford. 2005. Covalent protein immobilization on glass surfaces: Application to alkaline phosphatase. J. Biotechnol. 118:265-269.

Wang, A., H. Tang, T. Cao, S. O. Salley, and K. Y. S. Ng. 2005. In vitro stability study of organosilane self-assemble monolayers and multilayers. J. Colloid Interface Sci. 291:438-447.

Wang, Y., H. Chen, Y. Xiao, C. H. Ng, T. S. Oh, T. T. Y. Tan, and S. C. Ng. 2011. Preparation of cyclodextrin chiral stationary phases by organic soluble catalytic 'click' chemistry. Nat. Protoc. 6:935-942. 